\title{
Efficacy of nystatin for the treatment of oral candidiasis: a systematic review and meta-analysis
}

\author{
This article was published in the following Dove Press journal: \\ Drug Design, Development and Therapy \\ 16 March 2016 \\ Number of times this article has been viewed
}

Xin Lyu

Chen Zhao

Zhi-min Yan

Hong Hua

Department of Oral Medicine, Peking University School and Hospital of Stomatology, Beijing, People's Republic of China
Correspondence: Hong Hua;

Zhimin Yan

Department of Oral Medicine, Peking

University School and Hospital of Stomatology, 22 Zhongguancun Avenue South, Haidian District, Beijing 10008I,

People's Republic of China

Tel +861082195363

Fax +861062I 73402

Email honghua1968@aliyun.com;

yzhimin96@163.com
Objective: To systematically review and assess the efficacy, different treatment protocols (formulation, dosage, and duration), and safety of nystatin for treating oral candidiasis.

Methods: Four electronic databases were searched for trials published in English till July 1, 2015. Randomized controlled trials comparing nystatin with other antifungal therapies or a placebo were included. Clinical and/or mycological cure was the outcome evaluation. A meta-analysis or descriptive study on the efficacy, treatment protocols, and safety of nystatin was conducted.

Results: The meta-analysis showed that nystatin pastille was significantly superior to placebo in treating denture stomatitis. Nystatin suspension was not superior to fluconazole in treating oral candidiasis in infants, children, or HIV/AIDS patients. The descriptive investigations showed that administration of nystatin suspension and pastilles in combination for 2 weeks might achieve a higher clinical and mycological cure rate, and using the nystatin pastilles alone might have a higher mycological cure rate, when compared with using nystatin suspensions alone. Nystatin pastilles at a dose of 400,000 IU resulted in a significantly higher mycological cure rate than that administrated at a dose of 200,000 IU. Furthermore, treatment with nystatin pastilles for 4 weeks seemed to have better clinical efficacy than treatment for 2 weeks. Descriptive safety assessment showed that poor taste and gastrointestinal adverse reaction are the most common adverse effects of nystatin.

Conclusion: Nystatin pastille was significantly superior to placebo in treating denture stomatitis, while nystatin suspension was not superior to fluconazole in treating oral candidiasis in infants, children, or HIV/AIDS patients. Indirect evidence from a descriptive study demonstrated that administration of nystatin pastille alone or pastille and suspension in combination is more effective than that of suspension alone; prolonged treatment duration for up to 4 weeks can increase the efficacy of nystatin. More well designed and high quality randomized control studies are needed to confirm these findings.

Keywords: nystatin, oral candidiasis, systematic review, meta-analysis, safety, dosage forms, treatment duration

\section{Introduction}

Oral candidiasis, which is the most common human fungal infection, is characterized by an overgrowth of Candida species in the superficial epithelium of the oral mucosa.,2 It has been associated with multiple host risk factors, including impaired salivary gland function, denture wearing, oral mucosa disruption, drug use (long-term administration of broad-spectrum antibiotics, corticosteroids, antidepressants, antineoplastic, drugs, and immunosuppressant), age (common in neonates and the elderly), endocrine alterations (diabetes mellitus, pregnancy, renal failure, and hyperthyroidism), dietary factors (highcarbohydrate diet and iron-deficiency anemia), cancer, and HIV infection. ${ }^{3-5}$ Elimination of the predisposing factors is an important strategy in treating oral candidiasis. 
Various topical and systemic agents are currently available for the treatment of oral candidiasis. ${ }^{3}$ Systemic antifungal agents, including triazoles, fluconazole, and itraconazole, are appropriate for patients who do not respond to or are intolerant to topical treatment and those at high risk of developing systemic infections. ${ }^{3,6}$ However, numerous drug interactions and decreased susceptibility of species other than Candida albicans toward azoles limit the application of systemic antifungal agents. ${ }^{7,8}$ Topical antifungal agents, such as nystatin, amphotericin B, miconazole, and clotrimazole, are recommended typically as the first-line treatment for uncomplicated cases of oral candidiasis., ${ }^{2,9,10}$

Nystatin is a membrane-active polyene macrolide produced by Streptomyces noursei strains and is available in various forms, such as oral suspension, topical cream, and oral pastille. ${ }^{11-15}$ Nystatin is not absorbed from gastrointestinal tract when orally administered. ${ }^{5}$ Therefore, the topical use of nystatin is considered the most common route of administration in dentistry, as systemic exposure is minimal. Further, nystatin also plays an important role in the prophylaxis of oral and systemic candidiasis in full-term and premature newborns, infants, and immunocompromised patients (eg, AIDS patients, cancer patients, and organ transplant recipients), as it is associated with a low incidence of drug interactions and acceptable costs, especially in developing countries. ${ }^{16-19}$ The common recommended dose for topical use of nystatin is 200,000-600,000 IU qid for children and adults, and 100,000-200,000 IU qid for newborns and infants. ${ }^{18,20}$ Treatment duration can vary from 1 or 2 to 4 weeks. ${ }^{5,21-23}$ Up to now, there is no consensus on the formulation, dosage, or treatment duration of nystatin in the treatment of oral candidiasis. The aim of this study was to summarize and assess the efficacy, different treatment protocols (formulation, dosage, and duration), and safety of nystatin in different patient populations with oral candidiasis by a meta-analysis and systematic review.

\section{Materials and methods}

This review was performed according to the Preferred Reporting Items for Systematic Reviews and Meta-Analyses guidelines. ${ }^{24}$

\section{Inclusion criteria}

Randomized controlled trials that compared nystatin (at any dosage and in any form) with other antifungal therapies or a placebo were included in this review. The diagnosis of oral candidiasis was based on clinical diagnosis with or without confirmation by mycological tests. There were no restrictions on patients' age, sex, or race. The primary outcome was the clinical cure rate: the patient was considered to be cured if the oral lesion and symptoms had completely resolved. The secondary outcome was the mycological cure rate: the patient was considered to be cured if the smear or culture test showed negative results.

\section{Database and search strategies}

Four electronic databases were searched by two independent reviewing authors (XL, CZ): the Cochran Central Register of Controlled Trials (CENTRAL) (The Cochrane Library 2015, Issue 6), PubMed (July 1, 2015), EMBASE (July 1, 2015), and Science Citation Index (July 1, 2015). The following terms were searched in combination: ("oral candidiasis" OR "oral candidiases" OR "thrush" OR "oral moniliases" OR "oral moniliasis" OR "oropharyngeal candidiasis" OR "candidal stomatitis" OR "muguet" OR "prosthetic stomatitis" OR "angular cheilitis" OR "rhomboid glossitis") AND ("nystatin" OR "fungicidin") AND ("randomized controlled trial" OR "randomized controlled study" OR "RCT"). Manual searches were also conducted as a supplement.

\section{Data extraction and quality assessment}

The two review authors (XL, CZ) were independently responsible for scanning titles and abstracts, selecting studies, reading full reports, extracting data, and assessing the quality of studies; these steps were performed in duplicate by each of these authors. All the relevant data of each included study, including author, year of publication, region, risk factors, characteristics of the patients, detailed interventions, outcomes, and adverse effects, were extracted and summarized in a table format. The quality of the included studies was assessed using the Cochrane Handbook for Systematic Review of Interventions and the Rev Man 5.2.0 software. The following assessment criteria were used to assess the quality of the studies: 1) random sequence generation (if the study did not use this method, it was considered to have a selection bias), 2) allocation concealment (selection bias), 3) blinding of participants and personnel (performance bias), 4) blinding of outcome assessment (detection bias), 5) incomplete outcome data (attrition bias), 6) selective reporting (reporting bias), and 7) other biases. The Kappa coefficient was used to calculate inter-rater agreement with regard to study inclusion and quality assessment. A third reviewer (HH or ZMY) was invited to make an assessment if the two review authors could not reach a consensus.

\section{Data synthesis and analysis}

The efficacy of nystatin versus placebo and nystatin versus fluconazole was evaluated using the Stata 12.0 (StataCorp LP, College Station, TX, USA) software. Results were expressed 
as odds ratio (OR) together with the $95 \%$ confidence interval (CI), and plotted on a forest plot. The inconsistency index $I^{2}$ was calculated to assess the variation caused by heterogeneity. When $P$ was $>0.10$ and $I^{2}$ was $<25 \%$, the fixed-effect model was used, which assumes the same homogeneity of effect size across all studies. When $P$ was $<0.10$ and $I^{2}$ was $>25 \%$, inter-study heterogeneity was deemed statistically significant, and a random-effects model was employed. ${ }^{25}$ A descriptive study was conducted on studies evaluating the efficacy of nystatin versus other antifungal treatments due to the limited number of studies or marked heterogeneity in many aspects of the study characteristics.

\section{Results}

\section{Results of the search}

A total of 379 abstracts were extracted from the four databases. Finally, only eleven trials with a total of 1,148 patients were included in the present analysis (Figure 1). On the basis of the inclusion criteria, 153 duplicate publications, 182 irrelevant studies, four reviews, four nonclinical studies, four noncontrolled studies, one retrospective study, 12 studies with an unmatched study design, five studies with unavailable full texts, and three publications that were not in English were excluded. The Kappa value of inter-reviewer agreement for study inclusion was 0.83 . No studies that met the requirements were obtained by the manual search.

\section{Characteristics of the included studies}

Three trials were performed in patients with denture stomatitis, ${ }^{26-28}$ three trials were conducted on infants or

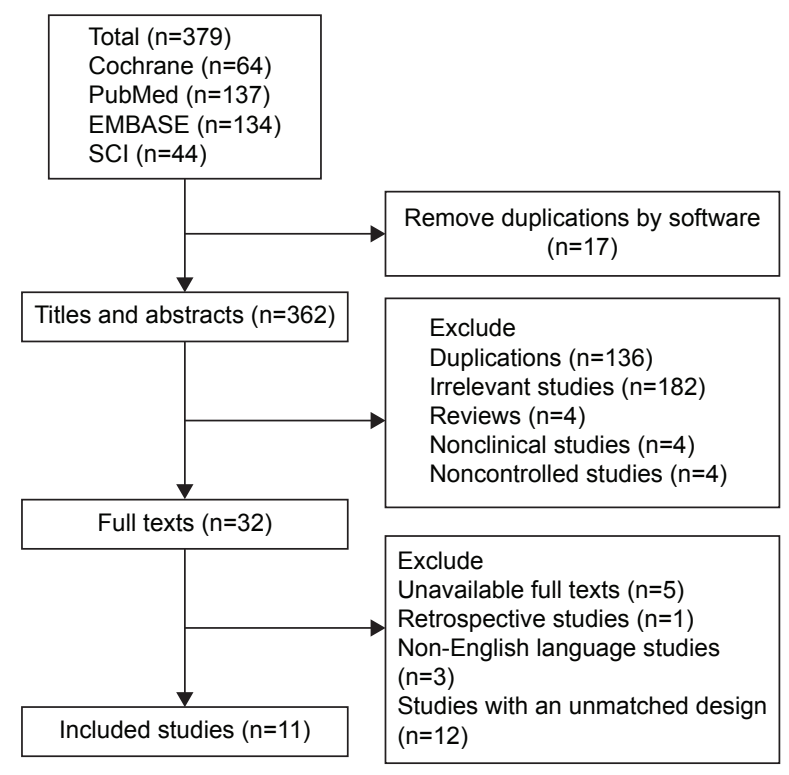

Figure I Trial flow and study selection. Abbreviation: $\mathrm{SCl}$, Science Citation Index. children; ${ }^{20,29,30}$ three trials included HIV or AIDS patients, ${ }^{31-33}$ one trial was on hospitalized cancer patients; ${ }^{34}$ and one trial was performed in several groups of patients, including those with xerostomia, HIV, immunosuppression in conjunction with organ transplantation, and wearing of dentures. ${ }^{35}$ Nystatin was used in the suspension and pastille forms; the dosage ranged from 100,000 to 1,100,000 IU three to five times a day; and the treatment duration was 10 to 30 days (Table 1).

\section{Risk of bias and quality of the included studies}

None of the included studies met all the seven assessment criteria (Table S1). Most studies were found to have a high risk of a performance and attrition bias and a moderate risk of other biases. The overall risk of each bias is presented in Figure 2, and the risk of each bias in each of the studies separately is presented in Figure 3. A 100\% agreement was achieved on study quality among the reviewers.

\section{Efficacy assessment}

The clinical and mycological cure rates associated with nystatin and the control treatments are summarized in Table 2. Two studies comparing the efficacy of nystatin pastilles to the placebo in treating denture stomatitis were analyzed by meta-analysis. ${ }^{27,28}$ The results showed that the efficacy of nystatin pastilles was significantly superior to that of the placebo treatment (clinical OR $=5.24,95 \% \mathrm{CI}=1.37-20.08$, $P=0.957$; mycological OR $=8.50,95 \% \mathrm{CI}=2.14-33.84$, $P=0.295$; Figure 4A and B; Table 3 ). Three studies evaluating the efficacy of nystatin suspension and fluconazole for treating oral or oropharyngeal candidiasis in infants, children ( 1 month to 13 years old), and HIV/AIDS patients were also studied by meta-analysis. ${ }^{29,30,32}$ The results of these three studies demonstrated that the efficacy of the nystatin suspension was significantly inferior to that of fluconazole (clinical OR $=0.11,95 \% \mathrm{CI}=0.06-0.20, P=0.253$; mycological OR $=0.04,95 \% \mathrm{CI}=0.02-0.09, P=0.908$; Figure $4 \mathrm{C}$ and D; Table 3).

A descriptive investigation was conducted on the other seven studies due to the limited number of studies or marked heterogeneity in many aspects of the study characteristics..$^{20,26,28,31,33-35}$ The efficacy of nystatin pastilles was compared to that of other drugs in two studies. ${ }^{28,34}$ The results showed that nystatin pastilles had similar clinical efficacy $(79.6 \%-87.5 \%)$ to amphotericin B $(88.8 \%)^{28}$ and ketoconazole $(72.2 \%){ }^{34}$ The efficacy of nystatin suspension was compared to that of other treatment strategies in four studies. $^{20,26,31,33}$ These studies showed that the clinical and mycological efficacy of nystatin suspensions (9\%-54.1\% 


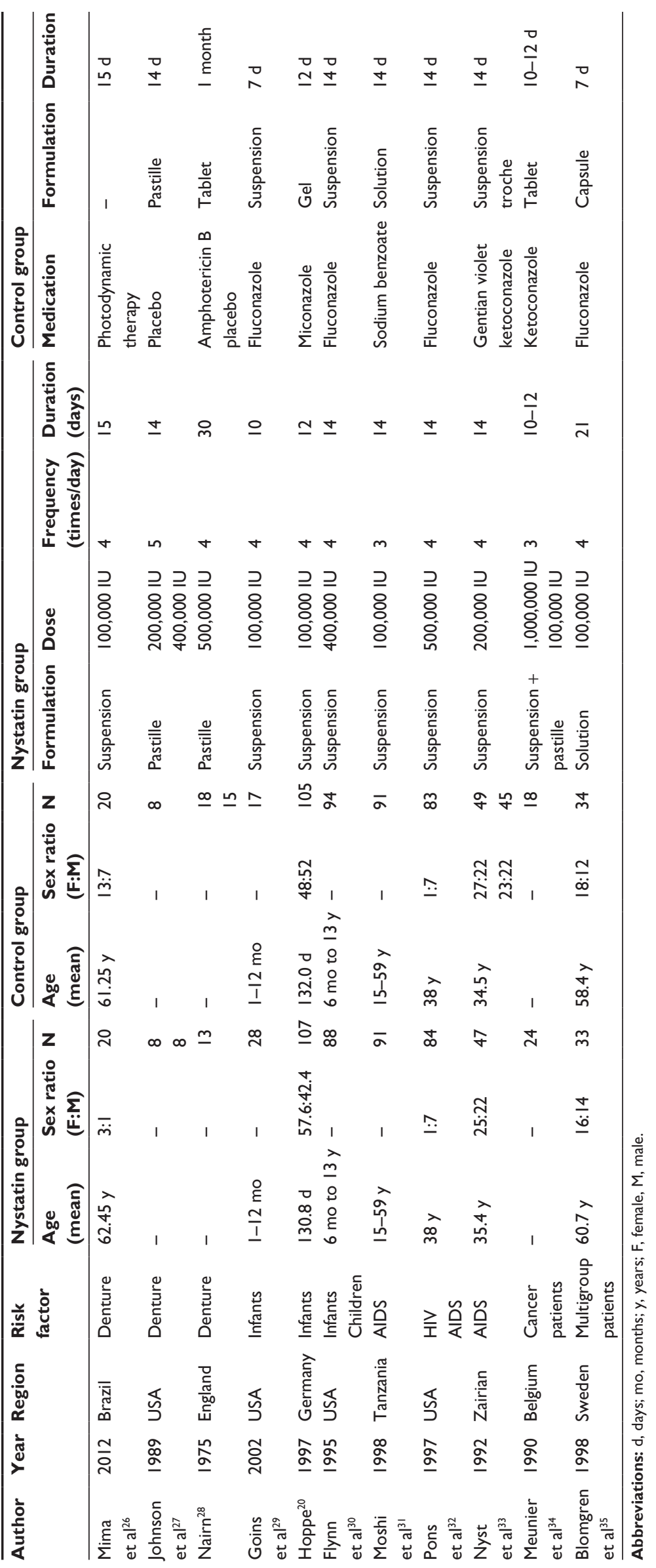




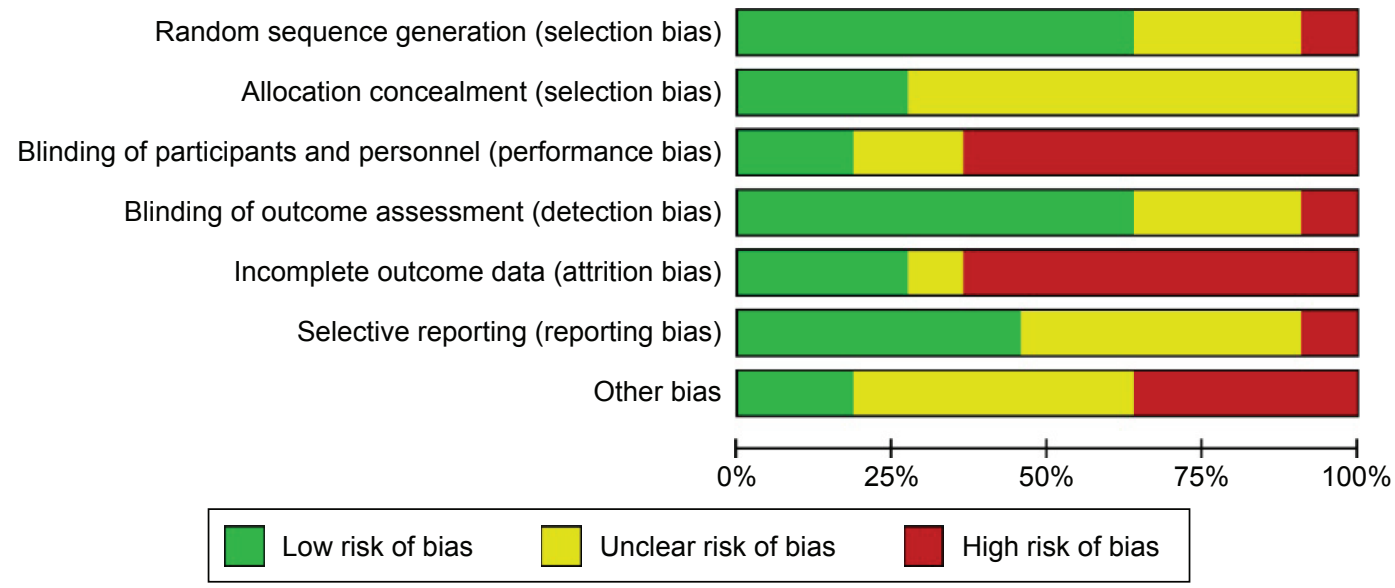

Figure 2 Risk of bias graph: the overall risk of each bias is presented as a percentage representing the risk in all the included studies.

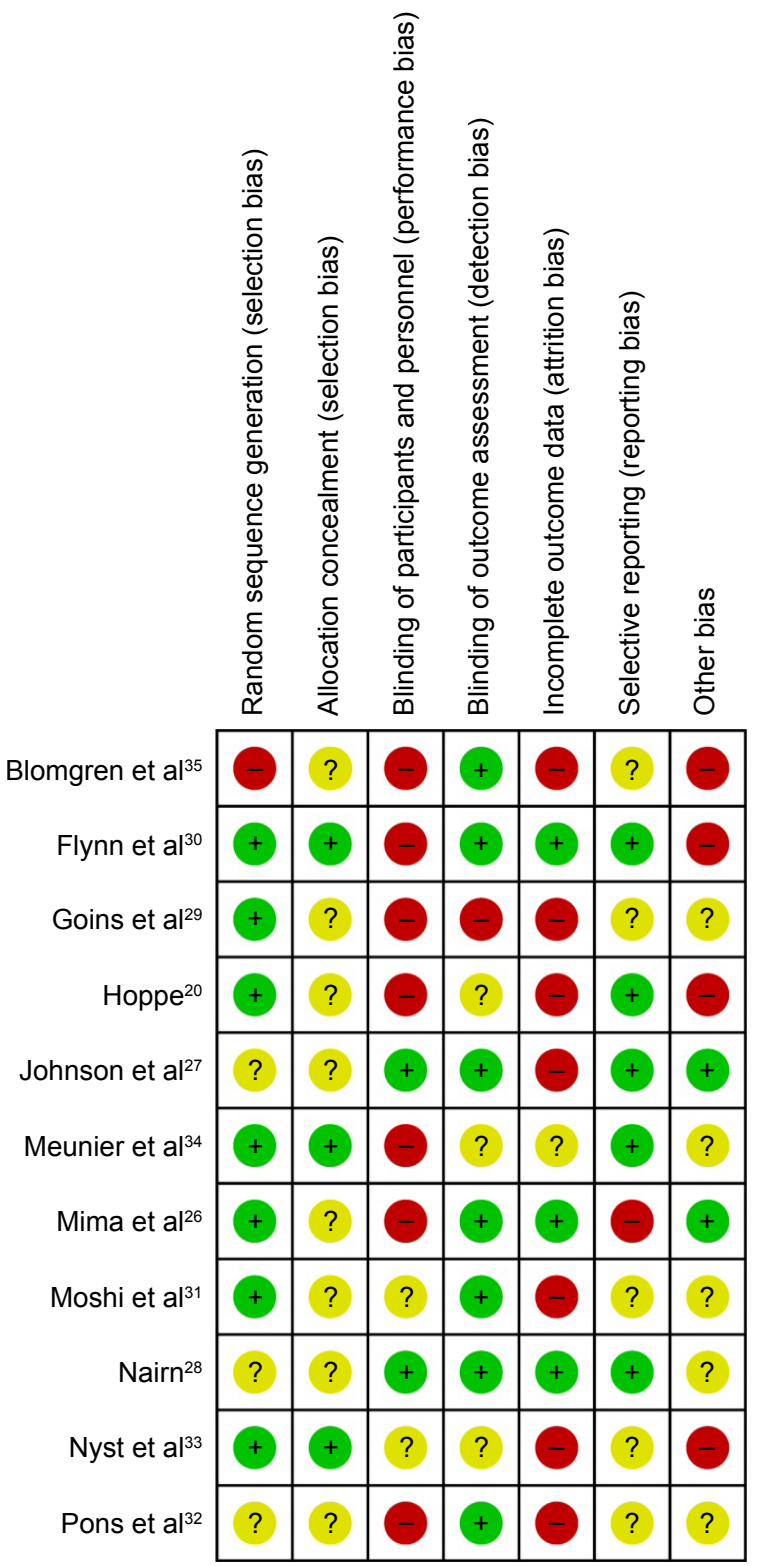

Figure 3 Risk of bias summary: the risk of each bias in each of the included studies is shown separately.

Note: +, ?, - indicate the low bias, uncertain, and high bias, respectively. and $5.6 \%-13 \%$, respectively) was significantly inferior to that of miconazole (99\% and $54.1 \%$, respectively), ${ }^{20}$ gentian violet ( $42 \%$ and $62 \%$, respectively), and ketoconazole (43\% and $57 \%$, respectively) ${ }^{33}$ in treating oral candidiasis in infants, children, and HIV/AIDS patients, while nystatin suspensions had similar clinical efficacy (53\%-63.5\%) to photodynamic therapy $(45 \%)^{26}$ and sodium benzoate $(55.6 \%) .{ }^{31}$ These results showed that nystatin pastilles had a relatively high clinical efficacy $(79.6 \%-87.5 \%)$ in treating oral candidiasis. However, nystatin suspension seemed to be inferior to miconazole, gentian violet, and ketoconazole in treating oral candidiasis in infants, children, and HIV/AIDS patients (for details, Tables 1 and 2).

\section{Formulation, dosage, and duration of nystatin treatment}

Due to obvious diversity in study design, the analysis of different treatment protocols (formulation, dosage, and duration) of nystatin was not qualified for meta-analysis; only descriptive investigations were conducted. In the included eleven studies, there are three formulations of nystatin, including suspension form, pastille form, and a combination of the suspension and pastille forms. For patients with denture stomatitis, the clinical cure rate with the suspension form was $53 \%,{ }^{26}$ and the clinical and mycological cure rates with the pastille form only were $14.3 \%-76.9 \%$ and $40 \%-71.4 \%$, respectively. ${ }^{27,28}$ Researches on infants, children, and HIV/AIDS patients with oral candidiasis showed that the clinical cure rate was $9 \%-63.5 \%$ and the mycological cure rate was $5.6 \%-13 \%$ with the use of the suspension form. ${ }^{20,29-33}$ Meunier et $\mathrm{al}^{34}$ found that clinical and mycological cures were achieved in $87.5 \%$ and $66 \%$ of cancer patients, respectively, with oral candidiasis by using the suspension and pastille forms in combination. The results of these studies indicated that combined administration of 
Table 2 Clinical and mycological efficacy of nystatin and the control treatments

\begin{tabular}{|c|c|c|c|c|c|c|c|}
\hline \multirow[t]{2}{*}{ Author } & \multirow[t]{2}{*}{ Risk factor } & \multicolumn{3}{|c|}{ Clinical cure rate } & \multicolumn{3}{|c|}{ Mycological cure rate } \\
\hline & & $\begin{array}{l}\text { Nystatin } \\
\text { (\%) }\end{array}$ & $\begin{array}{l}\text { Control } \\
\text { (\%) }\end{array}$ & OR (95\% Cl) & $\begin{array}{l}\text { Nystatin } \\
\text { (\%) }\end{array}$ & $\begin{array}{l}\text { Control } \\
\text { (\%) }\end{array}$ & OR (95\% Cl) \\
\hline Mima et al ${ }^{26}$ & Denture & 53 & 45 & $1.22(0.35-4.24)$ & - & - & - \\
\hline \multirow[t]{2}{*}{ Johnson et $\mathrm{a}^{27}$} & Denture & 28.6 & 0 & $7.73(0.31-193.44)$ & 57.1 & 0 & $21.86(0.91-523.42)$ \\
\hline & & 14.3 & 0 & $3.92(0.14-112.90)$ & 71.4 & 0 & 37.40 (1.49-936.27) \\
\hline \multirow[t]{2}{*}{ Nairn ${ }^{28}$} & Denture & 76.9 & 88.8 & $0.42(0.06-2.95)$ & 40 & 6.25 & $10.00(0.92-108.82)$ \\
\hline & & 76.9 & 40 & $5.00(0.96-26.11)$ & 40 & 20 & $2.67(0.36-19.71)$ \\
\hline Goins et $\mathrm{al}^{29}$ & Infants & 28.6 & 100 & $0.01(0.00-0.26)$ & 5.6 & 73.3 & $0.07(0.01-0.64)$ \\
\hline Hoppe ${ }^{20}$ & Infants & 54.1 & 99 & $0.01(0.00-0.09)$ & 8.2 & 54.1 & $0.08(0.03-0.18)$ \\
\hline Flynn et $\mathrm{al}^{30}$ & Infants and children & 51 & 91 & $0.11(0.04-0.25)$ & II & 76 & $0.04(0.01-0.11)$ \\
\hline Moshi et al $\left.\right|^{31}$ & AIDS & 63.5 & 55.6 & $1.24(0.65-2.37)$ & - & - & - \\
\hline Pons et $\mathrm{al}^{32}$ & HIVIAIDS & 52 & 87 & $0.16(0.07-0.38)$ & 6 & 60 & $0.04(0.01-0.13)$ \\
\hline \multirow[t]{2}{*}{ Nyst et $\mathrm{al}^{33}$} & AIDS & 9 & 42 & $0.13(0.03-0.67)$ & 13 & 62 & $0.09(0.02-0.40)$ \\
\hline & & 9 & 43 & $0.12(0.02-0.66)$ & 13 & 57 & $0.12(0.03-0.50)$ \\
\hline Meunier et $\mathrm{al}^{34}$ & Cancer patients & 87.5 & 72.2 & $2.69(0.55-13.20)$ & 66 & 61 & $1.27(0.36-4.54)$ \\
\hline Blomgren et $\mathrm{a}^{35}$ & Multigroup patients & 16.7 & 30 & $0.47(0.14-1.61)$ & - & - & - \\
\hline
\end{tabular}

Abbreviations: $\mathrm{Cl}$, confidence interval; OR, odds ratio.

nystatin in the suspension and pastille form for 2 weeks might achieve a higher clinical and mycological cure rate than administration of the nystatin suspension alone in the treatment of oral candidiasis. Moreover, use of the pastille alone for 2 weeks might result in a higher mycological cure rate than use of the suspension alone (Table 4).

Johnson et $\mathrm{a}^{27}$ compared the efficacy of the nystatin pastilles administered in two dosages (200,000 and 400,000 IU) for treating denture stomatitis. No significant difference was found in clinical efficacy $(28.6 \%$ and $14.3 \%, \mathrm{OR}=5.67$, $95 \% \mathrm{CI}=0.56-56.96$ ) between the two dosages, while the mycological efficacy of the 400,000 IU nystatin pastilles was significantly higher than that of the 200,000 IU pastilles (71.4\% and 57.1\%, OR $=28.33,95 \% \mathrm{CI}=2.95-271.81$ ).

The treatment duration of nystatin was 2 to 4 weeks. Researches on denture stomatitis and oral candidiasis in infants, children, and HIV/AIDS patients showed that the clinical and mycological cure rates were $9 \%-63.5 \%$ and $6 \%-13 \%$, respectively, with the use of the suspension form for 2 weeks. ${ }^{30-33}$ Blomgren et al ${ }^{35}$ found that a $16.7 \%$ clinical cure rate was achieved when the suspension form was used for 3 weeks. Studies on denture stomatitis showed that using nystatin pastilles for 2 weeks could achieve a $14.3 \%-28.6 \%$ clinical cure rate and a 57.1\%-71.4\% mycological cure rate ${ }^{27}$ and that using the pastille form for 4 weeks could achieve a $76.9 \%$ clinical cure rate and a $40 \%$ mycological cure rate. ${ }^{28}$ These findings indicated that nystatin administration of 4 weeks has a better clinical efficacy than 2 weeks in the treatment of denture stomatitis (Table 4).

\section{Safety assessment}

Eight out of the eleven studies reported the adverse effects of nystatin. ${ }^{20,28-33,35}$ Two of the eight studies reported that nystatin had no adverse effects. ${ }^{29,33}$ One study did not show the details of the adverse effects. ${ }^{31}$ Poor taste (the incidence was $61.5 \%$ in one study $)^{28}$ and gastrointestinal adverse reactions, including vomiting, nausea, diarrhea, anorexia, and abdominal pain (the incidence was $0.01 \%-0.06 \%$ in four studies), were the most common adverse effects reported (Table 5). ${ }^{20,30,32,35}$

\section{Discussion}

Oral candidiasis is an opportunistic infection of oral cavity. It is common among the elderly and infants, particularly in those elderly patients who wear dentures. It can also be a mark of some systemic disease, such as diabetes mellitus, cancer, and immunodeficiency diseases. The prevalence and incidence of all forms of oral candidiasis have increased in recent decades. Approximately $54 \%$ of people who wear removable dentures suffer from oral candidiasis. ${ }^{36}$ Thrush occurs in $~ 1 \%$ to $37 \%$ of systematically healthy infants. ${ }^{29}$ In all, $15 \%-60 \%$ of cancer patients will develop oral candidiasis because of immunosuppression. ${ }^{2}$ More than $90 \%$ of patients with AIDS may suffer from oral candidiasis at some time during their illness. ${ }^{37}$ Although the appearance and development of azoles and echinocandins antifungal agents, which had better tastes and less gastrointestinal adverse reactions, provided more clinical options, topical therapy, such as nystatin, is still one of the main recommended treatments for oral candidiasis due to its high efficacy, low cost, and less side effects, especially 


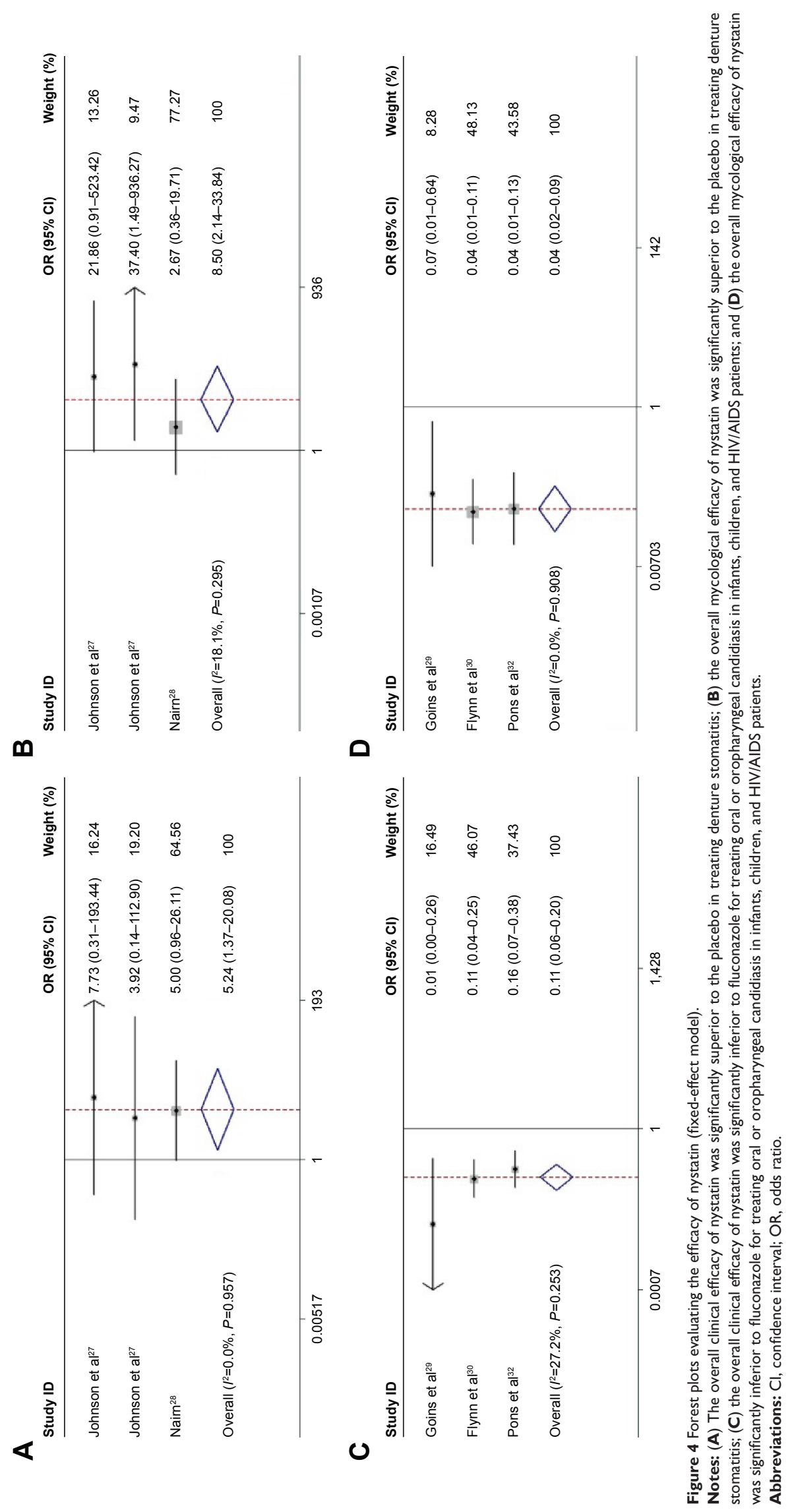


Table 3 Meta-analysis of the efficacy of nystatin compared with that of the placebo and fluconazole

\begin{tabular}{|c|c|c|c|c|c|c|c|c|c|}
\hline \multirow[t]{2}{*}{ Risk factor } & \multirow[t]{2}{*}{ Control } & \multirow{2}{*}{$\begin{array}{l}\text { Study } \\
\text { number }\end{array}$} & \multirow{2}{*}{$\begin{array}{l}\text { Patient } \\
\text { number }\end{array}$} & \multicolumn{3}{|l|}{ Clinical cure rate } & \multicolumn{3}{|c|}{ Mycological cure rate } \\
\hline & & & & OR $(95 \% \mathrm{Cl})$ & $P$-value & $I^{2}(\%)$ & OR $(95 \% \mathrm{Cl})$ & $P$-value & $I^{2}(\%)$ \\
\hline Denture & Placebo & $3 *$ & 52 & $5.24(1.37-20.08)$ & 0.957 & 0.0 & $8.50(2.14-33.84)$ & 0.295 & 18.1 \\
\hline $\begin{array}{l}\text { Infants, children } \\
\text { HIV/AIDS }\end{array}$ & Fluconazole & 3 & 394 & $0.11(0.06-0.20)$ & 0.253 & 27.2 & $0.04(0.02-0.09)$ & 0.908 & 0.0 \\
\hline
\end{tabular}

Note: *One study was divided into two investigations and included in the meta-analysis.

Abbreviations: $\mathrm{Cl}$, confidence interval; OR, odds ratio.

in developing countries. ${ }^{11,18}$ One study showed that nystatin was the most commonly prescribed antifungal agent for the treatment of oral candidiasis in Jordan $(78.2 \%){ }^{38}$

In 2009, the Infectious Diseases Society of America updated its clinical practice guidelines for the management of candidiasis. In this guideline, nystatin suspension at a concentration of $100,000 \mathrm{U} / \mathrm{mL}$ and a dosage of $4-6 \mathrm{~mL}$ qid, or one to two nystatin pastilles (200,000 $\mathrm{U}$ each) administered qid for 7-14 days, is recommended for mild oropharyngeal candidiasis. ${ }^{39}$ In addition, the World Health Organization recommended that topical therapy with nystatin suspension or pastilles can be an alternative to oral fluconazole for treating oropharyngeal candidiasis in HIV-positive children and adults. ${ }^{40}$ Even so, few evidences were found on the efficacy of nystatin for oral candidiasis in clinical practice. Furthermore, the applications of nystatin were varied among different patient populations and countries. So, ensuring the detailed indications of nystatin for different types of oral candidiasis is of great importance.

In the present review, the meta-analysis of the limited studies showed that the efficacy of nystatin pastilles was significantly superior to placebo in treating denture stomatitis, while nystatin suspension was not superior to fluconazole in treating oral candidiasis in infants, children, or HIV/AIDS patients. Further, the descriptive investigations showed that administration of nystatin suspension and pastilles in combination for 2 weeks might achieve a higher clinical and mycological cure rates $(87.5 \%$ and $66 \%)$ than if nystatin suspension alone is used. Nystatin pastilles at a dose of 400,000 IU resulted in a significantly higher mycological cure rate than the dose of 200,000 IU. With regard to treatment duration, administration of nystatin pastilles for 4 weeks showed better clinical efficacy (76.9\%) than its administration for 2 weeks. Poor taste and gastrointestinal adverse reaction were the most common adverse effects of nystatin.

Polyene antibiotics exert their antifungal effects by interacting with ergosterol in the fungal cell membrane, creating pores, and subsequently increasing the inflow and outflow of many materials. ${ }^{41}$ However, the treatment is effective only if these antibiotics are administered over a sufficient period of time. Nystatin suspension was not a good choice for infants, children, and HIV/AIDS patients with oral candidiasis, probably because of its short-term action on the oral mucosa. ${ }^{5}$ Moreover, exposure to nystatin at a concentration 0.25 to 1 times the minimum inhibitory concentration value for 30 minutes resulted in a postantifungal effect with an average duration range of 3.1 to 6.3 hours in several Candida isolates. ${ }^{16}$ Nystatin shows a remarkable postantifungal effect, which is defined as the delay in fungal regrowth that persists after a brief exposure to an antifungal agent. ${ }^{16}$ Therefore, nystatin in the topical pastille form seems to be more effective in treating oral candidiasis than oral nystatin suspension.

Candida species colonize in the oral mucosa via adhesion to buccal epithelial cells, germ tube formation, and relative cell surface hydrophobicity. ${ }^{42-45}$ Therefore, topical drugs that

Table 4 Summary of the usage and efficacy of nystatin

\begin{tabular}{lllllll}
\hline Risk factor & Formulation & Dose & $\begin{array}{l}\text { Frequency } \\
\text { (times/day) }\end{array}$ & $\begin{array}{l}\text { Duration } \\
\text { (days) }\end{array}$ & $\begin{array}{l}\text { Clinical cure rate } \\
\text { (\%) }\end{array}$ & $\begin{array}{l}\text { Mycological cure rate } \\
\text { (\%) }\end{array}$ \\
\hline Denture & Suspension & $100,000 \mathrm{IU}$ & 4 & 15 & 53 & - \\
& Pastille & $200,000 / 400,000 \mathrm{IU}$ & 5 & 14 & $28.6 / 14.3$ & $57.1 / 71.4$ \\
& Pastille & $500,000 \mathrm{IU}$ & 4 & 30 & 76.9 & 40 \\
Young age (in infants & Suspension & $100,000-400,000 \mathrm{IU}$ & 4 & $10-14$ & $28.6-54.1$ & $5.6-11$ \\
$\begin{array}{l}\text { and children) } \\
\text { HIVIAIDS }\end{array}$ & Suspension & $100,000-500,000 \mathrm{IU}$ & $3-4$ & 14 & $9-63.5$ & $6-13$ \\
Cancer & Suspension + pastille & $1,000,000+100,000 \mathrm{IU}$ & 3 & $10-12$ & 87.5 & 66 \\
Multiple & Suspension & $100,000 \mathrm{IU}$ & 4 & 21 & 16.7 & - \\
\hline
\end{tabular}


Table 5 Adverse effects of nystatin and the control treatments

\begin{tabular}{|c|c|c|c|}
\hline Author & Risk factor & Adverse effects of nystatin & Adverse effects of the control treatment \\
\hline Mima et $\mathrm{al}^{26}$ & Denture & - & - \\
\hline Johnson et $\mathrm{al}^{27}$ & Denture & - & - \\
\hline Nairn ${ }^{28}$ & Denture & Unpleasant taste in eight patients & Unpleasant taste in five patients \\
\hline Goins et $\mathrm{al}^{29}$ & Infants & None & None \\
\hline Hoppe ${ }^{20}$ & Infants & $\begin{array}{l}\text { Ten adverse events in six patients (vomiting, } \\
\text { diarrhea) }\end{array}$ & Seven events in six patients (vomiting, diarrhea) \\
\hline Flynn et $\mathrm{al}^{30}$ & $\begin{array}{l}\text { Young age (infants } \\
\text { and children) }\end{array}$ & $\begin{array}{l}\text { Three patients (vomiting, nausea, diarrhea, anorexia, } \\
\text { abdominal pain), one patient (rash, headache) }\end{array}$ & $\begin{array}{l}\text { Six patients (vomiting, nausea, diarrhea, anorexia, } \\
\text { abdominal pain), one patient (rash, headache) }\end{array}$ \\
\hline Moshi et $\mathrm{al}^{|3|}$ & AIDS & Ten patients & 14 patients \\
\hline Pons et $\mathrm{al}^{32}$ & HIV & Vomiting in one patient & $\begin{array}{l}\text { Nausea in one patient, and elevated liver enzyme } \\
\text { concentrations in two patients }\end{array}$ \\
\hline Nyst et $\mathrm{al}^{33}$ & AIDS & None & $\begin{array}{l}\text { Irritation and small superficial oral ulcers in two } \\
\text { patients }\end{array}$ \\
\hline Meunier et $\mathrm{al}^{34}$ & Cancer & - & - \\
\hline Blomgren et $\mathrm{al}^{35}$ & Multiple & Nausea in one patient & None \\
\hline
\end{tabular}

get absorbed into the oral epithelium are necessary for killing yeast hyphae growing within the tissue. ${ }^{23}$ In previous studies, the treatment duration of nystatin varied from 1 to 6 week(s). Richardson and Jones ${ }^{8}$ proposed that nystatin solutions need to be used for at least 1 week after resolution of symptoms, usually for 4 weeks for the primary treatment of oral candidiasis. Moreover, in recurrent cases, the duration of treatment should be at least 4 to 6 weeks. ${ }^{27}$ In agreement with these findings, in this review, our descriptive investigation showed that 4 weeks of nystatin administration seemed to have better clinical efficacy than 2 weeks of nystatin usage.

There are two limitations to this analysis. First, very few clinical trials with heterogeneity were available. Second, several studies were considered to be at a high risk of performance and attrition bias, and at a moderate risk of other biases. Moreover, $72.7 \%$ of the studies did not provide enough information about allocation concealment. The inconsistent quality of the included studies would impact the credibility of the results. Therefore, clinicians need to view the results of this research with caution. All these deficiencies indicate that well designed and high quality randomized controlled trial a study are needed in the future.

\section{Conclusion}

Nystatin pastille was significantly superior to placebo in treating denture stomatitis, while nystatin suspension was not superior to fluconazole in treating oral candidiasis in infants, children, or HIV/AIDS patients. Indirect evidence from a descriptive study demonstrated that administration of nystatin pastille alone or pastille and suspension in combination is more effective than that of suspension alone; prolonged treatment duration for up to 4 weeks can increase the efficacy of nystatin. More well designed and high quality randomized control studies are needed to confirm these findings.

\section{Acknowledgment}

This work was supported by the Program for New Clinical Techniques and Therapies of Peking University School and Hospital of Stomatology (PKUSSNCT-14A01) and Natural Science Foundation of China (81000441, 81570985).

\section{Disclosure}

The authors report no conflicts of interest in this work.

\section{References}

1. Melkoumov A, Goupil M, Louhichi F, Raymond M, de Repentigny L, Leclair G. Nystatin nanosizing enhances in vitro and in vivo antifungal activity against Candida albicans. J Antimicrob Chemother. 2013;68(9): 2099-2105.

2. Akpan A, Morgan R. Oral candidiasis. Postgrad Med J. 2002;78(922): 455-459.

3. Epstein JB, Polsky B. Oropharyngeal candidiasis: a review of its clinical spectrum and current therapies. Clin Ther. 1998;20(1):40-57.

4. Coronado-Castellote L, Jimenez-Soriano Y. Clinical and microbiological diagnosis of oral candidiasis. J Clin Exp Dent. 2013;5(5):e279-e286.

5. Samaranayake LP, Keung Leung W, Jin L. Oral mucosal fungal infections. Periodontol 2000. 2009;49:39-59.

6. Hoepelman IM, Dupont B. Oral candidiasis: the clinical challenge of resistance and management. Int J Antimicrob Agents. 1996;6(3) $155-159$.

7. Richardson MD, Warnock DW. Fungal Infection: Diagnosis and Management. Oxford: Blackwell Publishing; 2003.

8. Richardson MD, Jones BL. Therapeutic Guidelines in Systemic Fungal Infections. 3rd ed. London: Remedica Publishing; 2007.

9. Antifungal chemotherapy in patients with acquired immunodeficiency syndrome. British Society for Antimicrobial Chemotherapy Working Party. Lancet. 1992;340(8820):648-651.

10. Como JA, Dismukes WE. Oral azole drugs as systemic antifungal therapy. N Engl J Med. 1994;330(4):263-272. 
11. Kaur IP, Kakkar S. Topical delivery of antifungal agents. Expert Opin Drug Deliv. 2010;7(11):1303-1327.

12. Epstein JB. Antifungal therapy in oropharyngeal mycotic infections. Oral Surg Oral Med Oral Pathol. 1990;69(1):32-41.

13. Guida RA. Candidiasis of the oropharynx and esophagus. Ear Nose Throat J. 1988;67(11):832, 834-836, 838-840.

14. Greenspan D. Treatment of oropharyngeal candidiasis in HIV-positive patients. J Am Acad Dermatol. 1994;31(3 Pt 2):S51-S55.

15. Wong SSW, Samaranayake LP, Seneviratne CJ. In pursuit of the ideal antifungal agent for Candida infections: high-throughput screening of small molecules. Drug Discov Today. 2014;19(11):1721-1730.

16. Fernandez Campos F, Calpena Campmany AC, Rodriguez Delgado G, Lopez Serrano O, Clares Naveros B. Development and characterization of a novel nystatin-loaded nanoemulsion for the buccal treatment of candidosis: ultrastructural effects and release studies. JPharm Sci. 2012; 101(10):3739-3752.

17. Howell A, Isaacs D, Halliday R; Australasian Study Group For Neonatal I. Oral nystatin prophylaxis and neonatal fungal infections. Arch Dis Child Fetal Neonatal Ed. 2009;94(6):F429-F433.

18. Sklenar Z, Scigel V, Horackova K, Slanar O. Compounded preparations with nystatin for oral and oromucosal administration. Acta Pol Pharm. 2013;70(4):759-762.

19. Gotzsche PC, Johansen HK. Nystatin prophylaxis and treatment in severely immunodepressed patients. Cochrane Database Syst Rev. 2014; 9:CD002033.

20. Hoppe JE. Treatment of oropharyngeal candidiasis and candidal diaper dermatitis in neonates and infants: review and reappraisal. Pediatr Infect Dis J. 1997;16(9):885-894.

21. Niimi M, Firth NA, Cannon RD. Antifungal drug resistance of oral fungi. Odontology. 2010;98(1):15-25.

22. Williams DW, Kuriyama T, Silva S, Malic S, Lewis MA. Candida biofilms and oral candidosis: treatment and prevention. Periodontol 2000. 2011; 55(1):250-265.

23. Rautemaa R, Ramage G. Oral candidosis - clinical challenges of a biofilm disease. Crit Rev Microbiol. 2011;37(4):328-336.

24. Shamseer L, Moher D, Clarke M, et al. Preferred reporting items for systematic review and meta-analysis protocols (PRISMA-P) 2015: elaboration and explanation. BMJ. 2015;349:g7647.

25. Xie S, Xu H, Shan X, Liu B, Wang K, Cai Z. Clinicopathological and prognostic significance of survivin expression in patients with oral squamous cell carcinoma: evidence from a meta-analysis. PLoS One. 2015;10(2): 0116517

26. Mima EG, Vergani CE, Machado AL, et al. Comparison of photodynamic therapy versus conventional antifungal therapy for the treatment of denture stomatitis: a randomized clinical trial. Clin Microbiol Infect. 2012;18(10):E380-E388.

27. Johnson GH, Taylor TD, Heid DW. Clinical evaluation of a nystatin pastille for treatment of denture-related oral candidiasis. J Prosthetic Dent. 1989;61(6):699-703.

28. Nairn RI. Nystatin and amphotericin B in the treatment of denture-related candidiasis. Oral Surg Oral Med Oral Pathol. 1975;40(1):68-75.
29. Goins RA, Ascher D, Waecker N, Arnold J, Moorefield E. Comparison of fluconazole and nystatin oral suspensions for treatment of oral candidiasis in infants. Pediatr Infect Dis J. 2002;21(12):1165-1167.

30. Flynn PM, Cunningham CK, Kerkering T, et al. Oropharyngeal candidiasis in immunocompromised children: a randomized, multicenter study of orally administered fluconazole suspension versus nystatin. The Multicenter Fluconazole Study Group. J Pediatr. 1995;127(2):322-328.

31. Moshi AH, Jorgensen AF, Pallangyo K. Treatment of oral candidiasis: a study to determine the clinical response of sodium benzoate compared with nystatin suspension. AIDS. 1998;12(16):2237-2238.

32. Pons V, Greenspan D, Lozada-Nur F, et al. Oropharyngeal candidiasis in patients with AIDS: randomized comparison of fluconazole versus nystatin oral suspensions. Clin Infect Dis. 1997;24(6):1204-1207.

33. Nyst MJ, Perriens JH, Kimputu L, Lumbila M, Nelson AM, Piot P. Gentian violet, ketoconazole and nystatin in oropharyngeal and esophageal candidiasis in Zairian AIDS patients. Ann Soc Belg Med Trop. 1992; 72(1):45-52.

34. Meunier F, Gérain J, Snoeck R. Oral treatment of oropharyngeal candidiasis with nystatin versus ketoconazole in cancer patients. Drug Invest. 1990;2(2):71-75.

35. Blomgren J, Berggren U, Jontell M. Fluconazole versus nystatin in the treatment of oral candidosis. Acta Odontol Scand. 1998;56(4): 202-205.

36. Cumming CG, Wight C, Blackwell CL, Wray D. Denture stomatitis in the elderly. Oral Microbiol Immunol. 1990;5(2):82-85.

37. Feigal DW, Katz MH, Greenspan D, et al. The prevalence of oral lesions in HIV-infected homosexual and bisexual men: three San Francisco epidemiological cohorts. AIDS. 1991;5(5):519-525.

38. Al-Shayyab MH, Abu-Hammad OA, Al-Omiri MK, Dar-Odeh NS. Antifungal prescribing pattern and attitude towards the treatment of oral candidiasis among dentists in Jordan. Int Dent J. 2015;65(4):216-226.

39. Pappas PG, Kauffman CA, Andes D, et al. Clinical practice guidelines for the management of candidiasis: 2009 update by the Infectious Diseases Society of America. Clin Infect Dis. 2009;48(5):503-535.

40. WHO Guidelines Approved by the Guidelines Review Committee. Guidelines on the Treatment of Skin and Oral HIV-Associated Conditions in Children and Adults. Geneva: World Health Organization. Copyright (c) World Health Organization 2014; 2014.

41. Kinoshita H, Yoshioka M, Ihara F, Nihira T. Cryptic antifungal compounds active by synergism with polyene antibiotics. J Biosci Bioeng. Epub 2015 Aug 29.

42. Ellepola AN, Joseph BK, Chandy R, Khan ZU. The postantifungal effect of nystatin and its impact on adhesion attributes of oral Candida dubliniensis isolates. Mycoses. 2014;57(1):56-63.

43. Jayatilake JA, Samaranayake LP. Experimental superficial candidiasis on tissue models. Mycoses. 2010;53(4):285-295.

44. Sitheeque MA, Samaranayake LP. Chronic hyperplastic candidosis/ candidiasis (candidal leukoplakia). Crit Rev Oral Biol Med. 2003;14(4): 253-267.

45. Samaranayake LP, Fidel PL, Naglik JR, et al. Fungal infections associated with HIV infection. Oral Dis. 2002;8 Suppl 2:151-160. 


\section{Supplementary material}

Table SI Risk of bias and quality assessment of the included studies

\begin{tabular}{|c|c|c|c|c|c|c|c|}
\hline Author & $\begin{array}{l}\text { Random sequence } \\
\text { generation }\end{array}$ & $\begin{array}{l}\text { Allocation } \\
\text { concealment }\end{array}$ & $\begin{array}{l}\text { Blinding of participants } \\
\text { and personnel }\end{array}$ & $\begin{array}{l}\text { Blinding of outcome } \\
\text { assessment }\end{array}$ & $\begin{array}{l}\text { Incomplete } \\
\text { outcome data }\end{array}$ & $\begin{array}{l}\text { Selective } \\
\text { reporting }\end{array}$ & $\begin{array}{l}\text { Other } \\
\text { bias }\end{array}$ \\
\hline Mima et $\mathrm{a}^{26}$ & Low bias & Uncertain & High bias & Low bias & Low bias & High bias & Low bias \\
\hline Johnson et $\mathrm{al}^{27}$ & Uncertain & Uncertain & Low bias & Low bias & High bias & Low bias & Low bias \\
\hline Nairn ${ }^{28}$ & Uncertain & Uncertain & Low bias & Low bias & Low bias & Low bias & Uncertain \\
\hline Goins et $\mathrm{a}^{29}$ & Low bias & Uncertain & High bias & High bias & High bias & Uncertain & Uncertain \\
\hline Hoppe $^{20}$ & Low bias & Uncertain & High bias & Uncertain & High bias & Low bias & High bias \\
\hline Flynn et al ${ }^{30}$ & Low bias & Low bias & High bias & Low bias & Low bias & Low bias & High bias \\
\hline Moshi et $\mathrm{a}^{31}$ & Low bias & Uncertain & Uncertain & Low bias & High bias & Uncertain & Uncertain \\
\hline Pons et $\mathrm{al}^{32}$ & Uncertain & Uncertain & High bias & Low bias & High bias & Uncertain & Uncertain \\
\hline Nyst et al ${ }^{33}$ & Low bias & Low bias & Uncertain & Uncertain & High bias & Uncertain & High bias \\
\hline Meunier et $\mathrm{al}^{34}$ & Low bias & Low bias & High bias & Uncertain & Uncertain & Low bias & Uncertain \\
\hline Blomgren et $\mathrm{al}^{35}$ & High bias & Uncertain & High bias & Low bias & High bias & Uncertain & High bias \\
\hline
\end{tabular}

\section{Publish your work in this journal}

Drug Design, Development and Therapy is an international, peerreviewed open-access journal that spans the spectrum of drug design and development through to clinical applications. Clinical outcomes, patient safety, and programs for the development and effective, safe, and sustained use of medicines are a feature of the journal, which has also been accepted for indexing on PubMed Central. The manuscript management system is completely online and includes a very quick and fair peer-review system, which is all easy to use. Visit http://www.dovepress.com/testimonials.php to read real quotes from published authors.

Submit your manuscript here: http://www.dovepress.com/drug-design-development-and-therapy-journal 